changes in intraocular pressure occurring pari passu with changes of blood pressure are due to changes in volume of the intraocular blood-vessels, particularly of the venous system.

\title{
F. A. Williamson-Noble.
}

\section{BOOK NOTICES}

Annals of Eugenics. Edited by Karl Pearson and Ethel M. Elderton. Vol. II, Parts I and 2. From the Francis Galton Laboratory for National Eugenics. Cambridge: University Press. April, 1927.

Among the very interesting articles in this number of the "Annals of Eugenics" is one by Professor Karl Pearson and Miss Margaret Moul on the problem of alien immigration into Great Britain, illustrated by an examination of Russian and Polish Jewish children (Part III). This section of the investigation deals with the statistics of ocular characters. There can be no question that this paper is the most important, not only on the statistics of visual acuity in a particular large social group, but also in many other cognate respects, that has been published of recent years. It is not easy reading, and few ophthalmologists are qualified to follow the mathematical procedures, much less to criticize them. They can, however, have complete confidence in Professor Pearson in this matter. The only criticism which an ophthalmologist is justified in making will deal solely with the criteria which are submitted to statistical computation. The authors have adopted a very elaborate gamut of degrees of visual acuity founded on Snellen's notation (which we regret to see reduced to decimal form). It may be doubted whether such extreme refinement is justified in the somewhat uncertain data of hundreds of cases derived from different sources and examined by different observers.

Among the conclusions arrived at are the following : (a) myopia increases with age; $(b)$ mixed astigmatism tends to increase up to eleven years, and then to decrease and ultimately become steady in amount; $(c)$ hypermetropic astigmatism probably remains fairly constant after 9.5 years and may tend slightly to increase from 14 to $15 ;(d)$ manifest hypermetropia tends to increase from 9.5 to 13 years, but may remain constant after this. "Our new data confirm the old, in the view that the school cannot be looked upon as the forcing house of myopia." This view will certainly awaken qualms in the minds of ophthalmologists, only slightly modified by the emphatically expressed warning that "when we 
speak of 'increase of myopia' we mean the increase in the numbers recorded as myopic, the intensity of the myopia in the individual is not under consideration." As regards the latter point the deductions are that "the intensity of myopia increases with age, the intensity of hypermetropia decreases with age; the numbers of children who have manifest hypermetropia and myopia both increase, but the number of hypermetropic children is not only at every age greater than the number of myopic, but increases with age at a greater rate." Corneal refraction is found to vary little with age, and "there is small doubt that corneal astigmatism does not increase between the ages 8 to 15 years in the population considered."

Reference must be made to the original paper for the numerous inter-correlations of various ocular characters, which are admirably illustrated by graphs and diagrams. In this manner binocular vision and vision of best eye, visual acuity of right and left eye, visual acuity and general refraction, visual acuity and corneal refraction, visual acuity and general astigmatism, visual acuity and corneal astigmatism, general astigmatism and position of near point, accommodation and age, and several other pairs of factors are correlated. The paper ends with an important mathematical note on lenticular astigmatism.

Myelogenetisch-Anatomische Untersuchungen über den zentralen Abschnitt der Sehleitung. By Dr. PHIL and MED. Richard ARwed Pfeifer, Leipzig. Pp. 149, with 119 figures. Berlin : Julius Springer. 1925. Price 18 gold marks.

This volume of the series of monographs on neurology and psychiatry, edited by Professors O. Foerster of Breslau and K. Wilmanns of Heidelberg, cannot be neglected by any student of the intracerebral visual paths. It is an original investigation of the myelination of these paths, with special reference to those passing from the basal primary optic centres to the occipital lobes. It fittingly emanates from Professor Flechsig's Institute at Leipzig, and is in part founded upon his collection of myelogenic preparations. The monograph is the more valuable to ophthalmologists in that the original work is prefaced by a very complete account of the conflicting views of many distinguished neurologists, with copious quotations from their writings. Those who are familiar only with the relatively simple scheme advocated by Henschenwhich looms largest in most English textbooks-will be interested to read critical descriptions of the opinions of von Monakow, Wehrle, Minkowski, von Stauffenberg, Flechsig, Nissl von Mayendorf, Adolph Meyer, Brower, Heine, Lenz, Wilbrand, and others. Such a perusal will doubtless have a discencerting effect upon the self complacency induced by an accepted point of view; and it 
must be admitted that it is no easy matter to follow the arguments and unravel the complications, some of which are due to variations in the nomenclature of various tracts. Those, however, who undertake the task will be rewarded, and will recognize that Dr. Pfeifer has made a distinct step in advancing our knowledge of the subject. The book is admirably printed and illustrated; and contains an excellent bibliography.

Die Pathologie der Tränenorgane. By Prof. W. Sтоск, Tübingen. Part of Graefe-Saemisch Handbuch der gesamten Augenheilkunde. Pp. 170. Berlin: Julius Springer. 1925. Price 12 gold marks.

This monograph on the diseases of the lacrymal apparatus is an excellent résumé of the subject, well documented with bibliographies and admirably illustrated. The causes of abnormal increase and diminution of the secretion of tears, bloody tears, the action of tears on micro-organisms and the presence of antibodies in tears are first considered. The lacrymal glands, canaliculi, and sac are then successfully dealt with. The articles on dacryoadenitis in its various forms and dacryocystitis are particularly exhaustive.

Die Bestimmung des Astigmatismus durch Schattenprobe mit Cylindergläsern. By Prof. Dr. K. Lindner. Pp. 111 with 83 figures. Berlin: S. Karger. 1927.

Lindner's book opens with a short history of the performance of retinoscopy with cylinders and then goes on to an ingenious explanation of retinoscopy as a whole. The basis of this is, that in myopia a real image of the surgeon's mirror is formed in the patient's vitreous, and in hypermetropia a virtual image is formed behind the patient's eye. The image and the mirror form conjugate foci; and it is therefore only the light reflected from the patient's fundus in such a direction that it will pass through the hole in the image, which can pass through the hole in the surgeon's mirror and be seen by him. The apparent movement of this light, on tilting the mirror in myopia and hypermetropia can be deduced from what happens when the image is in front of or behind the retina respectively. The next part of the book concerns the practical side of skiascopy and is profusely illustrated with pictures of the various types of shadow that may be seen. The author favours the use of a plane mirror, and advises that the skiascopic distance shauld be not less than one metre. He is also an advocate of mydriasis and cycloplegia, because if the patient is not looking straight at the mirror, errors are likely to occur owing to the peripheral aberration of the eye and the production of radial astigmatism.

With regard to the use of cylinders the author claims no originality for this procedure, but considers that without a know- 
ledge of the underlying optical principles, it is difficult to interpret the skiascopical pictures produced. Once these principles are grasped, however, the procedure is quite simple. The results are more satisfactory than when spheres only are used, because the axis and amount of the correcting cylinder can be determined with greater accuracy.

This book is one of which we would welcome a translation, so that it might be available to a larger number of English readers. While one may not agree with all the statements made, the wealth of practical information contained within its one hundred and eleven pages cannot fail to be of value to ophthalmic surgeons.

Retrobulbar Neuritis of Nasal Origin. (Über die rhinogene Neuritis retrobulbaris.) By Prof. Dr. J. Meller and Dr. OSKar Hirsch. Pp. 62 with 8 text illustrations and 2 coloured plates. Berlin: S. Karger. 1926. Price 4.50 marks.

This work is divided into two parts, an ophthalmological section by Meller, and a rhinological one by Hirsch. The authors do not claim that any great amount of original matter is presented; the book is more in the nature of a digest of recent work on the subject, and is confined to material written in the German language. Although most of the references are given in the text, the absence of a complete bibliography will certainly be felt by the reader. Both authors lay stress on the point that it is impossible to decide without operation the question of the condition of the posterior ethmoidal cells. They also are both in favour of the method of prolonged anaemia (Daueranämasierung), by adrenaline tampons applied to the nasal mucous membrane for two hours daily, before deciding on the necessity for an operation. Cases to illustrate the success of this method are cited, and the reader is referred to an article by v. Herrenschwand in Dimmer's "Festschrift" for a full description of the method. The illustrations and plates are excellent.

\section{CORRESPONDENCE}

\section{PERSONAL EXPERIENCE OF CHRONIC DIPHTHEROID INFECTION OF EYELID}

To the Editor of The British Journal of Ophthalmology

Sir,-From October, 1922 to January 28,1924 , I suffered from repeated attacks of inflammation in the left upper eyelid, pus being expressible from the margin : cultures taken on three occasions 